Viewpoint

\title{
Millennium Development Goals
}

Pratik Khanal

BPH $22^{\text {nd }}$ Batch

\section{Introduction}

The Millennium declaration is a ground breaking international development agenda for the $21^{\text {st }}$ century. The eight MDGs to be achieved by 2015 respond to the world's most urgent development needs. As articulated in the Millennium declaration, the MDGs are based on fundamental values such as freedom, equity, democratic governance, the rule of law, respect for the human right and peace and security. Nepal is one of the 189 countries committed to the achievement of MDGs. Despite having to place its significant attention and resources on post-conflict reconstruction and rehabilitation as well as state reconstructing and constitution writing, Nepal has done well so far in its commitment to achieve MDGs.

The county's tenth plan (2002/3-2006/7) and Poverty Reduction Strategy Paper incorporated the MDGs into strategic framework where the main focus was on poverty reduction. The three year interim plan maintained its focus on poverty reduction and growth, emphasized a greater strategic presence for the state in development, especially of remote areas and socially marginalized groups.

\section{MDG-1: Eradicate extreme poverty and hunger}

Between 1996 and 2004, the level of poverty of poverty reduced by 11 percentage points from 42 to 31 percent and it has further reduced by 6 percentage points from 31 to 25 between 2004 and 2009. (NPC 2010). However with this positive trend, disparity between rural and urban areas still exists. Both the chronic and transitory food security has improved. However, there is a declining trend in production of some staple crops and some geographic areas are still facing chronic hunger. Underemployment has decreased while unemployment has increased. Growth in agriculture on which $74 \%$ of the population depends for its livelihood (CBS 2009) has been slow. Its contribution to GDP has declined to 32.8. From a regional perspective, the MidWestern Development region (MWDR) is the poorest. In 2004 , poverty in the MWDR was 44.8 percent, while it was 27.1 percent in the Central Development Region (CDR) and 3.3 percent in Kathmandu. Disparity between genders and caste/ ethnicities is also high and persistent. In addition, the gap between rich and poor is unacceptably high. The persistent level of economic disparity has had a consequential effect on other sectors such as education, health and the environment.Remittance money, which is the backbone of the rural economy, is steady. Nevertheless, the remittance growth rate is declining. Macroeconomic indicators show serious weakness while there is an unfavorable investment environment.

Target 1 A: Halve between 1990 and 2015, the proportion of people whose income is less than one dollar a day.

In 2005, the proportion of Nepal's population living on less than US one dollar per day was estimated to be $24.1 \%$ (CBS/ World Bank 2005) and 31\% were assessed to be below the national poverty line. The country's poverty level now is $25.4 \%$ (NPC 2010). The MDG target for the proportion of people living less than one dollar per day and below the national poverty line are 17 and 21 respectively.

Target 1 B: Achieve full and productive employment and decent work for all, including women and young people

The employment to population ratio dropped to $81.73 \%$ in 2008 from 84.3 in 1998 . With $85.5 \%$ for males and $78.5 \%$ for females employed (CBS 2009), $73.9 \%$ are involved in agriculture. At present, 12700 males and 126000 females are unemployed in Nepal. The MDG target of meeting full employment and decent work for all by 2015 is going to be difficult. The main challenge for Nepal has been lack of investment for employment generation, absence of adequate industrial security, political uncertainty which has compelled youth to seek employment abroad.

Target 1 C: Halve between 1990 and 2015, the proportion of people who suffer from hunger

Nepal has become food deficient since the 1990s. Annual food grain imports are estimated at 6, 00,000 tones $22.5 \%$ of population is undernourished against the MDG target of $25 \%$ by 2015 . The declining trend in the proportion of underweight and stunted children which are currently $29 \%$ and $41 \%$ respectively (NDHS 2011 Preliminary findings) suggests that the MDG target (29 and 30 respectively) will need strenuous efforts to achieve. High dependence on traditional agriculture, low productivity, small land holdings, low wages/ income, difficult terrains and lack of transport networks are major reasons causing food insecurity.

\section{MDG-2:Achieve universal primary education}

On primary education, it is quite possible that the MDG will be met. The net enrollment rate is increasing and, with some additional effort, the target could be met. However, greater 
effort will be needed to meet the rate required for survival of students beyond Grade 5. The target for literary among the 15-24 years age group, although currently below the 100 percent target, is likely to be met.

Target 2: Ensure that by 2015, children will be able to complete a full course of primary schooling

Net enrollment in primary and secondary education is $93.7 \%$ and $77.9 \%$ against the target of 96 and 85 by 2010 and hundred percent by 2015. According to MOE, more than 2,18,000 primary school aged children are still out of school. Continuation of scholarship to retain individuals in the educational system is required which is inadequate both in coverage and in the amounts distributed. Special need children like conflict affected, trafficked, working and street children should be also addressed. Physical capacity of school should be expanded to address overcrowding and urgent need to reduce repetition and dropout rates by making school environment more children friendly and conducive to learning.

\section{MDG-3: Promote gender equality and empower women}

Gender equality in education has improved substantially over the past five years, and the 2015 target regarding equal access of girls and boys to primary education has already has been achieved. It is likely to be achieved for secondary education as well. Women's participation in public life has also improved. Their presence in the formal labour force, including migrant workers, security forces and teaching is increasing, and their presence in the political domain has grown significantly over the last 3 years.

Target 3: Eliminate gender disparity in primary and secondary education, preferably by 2005, and in all levels of education by 2015

Girl focused initiatives have contributed to increasing girls enrollment in primary and secondary levels, concerted efforts are necessary to retain them and support them to complete school level education. With a ratio of women to men of 0.61 at higher secondary level and 0.63 at tertiary level, it will be difficult to achieve parity at these levels by 2015. Due to greater workloads and responsibilities and also early marriage, girls obviously face more challenge to stay in school and perform well.

MDG-4: Reduce Child mortality

The under-five mortality rate has decreased significantly and the target is likely to be met earlier than 2015.

Target 4: Reduce by two-thirds between 1990 and 2015 the Under 5 Mortality rate

To reduce mortality further among children in Nepal will require greater attention to the care of newborn and infants. According to the NDHS 2011 Preliminary findings, IMR has come down to 46 and Under five Mortality rate to 54 which suggests that MDG target of IMR and U5 MR( 36 and 54 respectively) will be achieved by 2015 . To control morbidity and mortality among children, the government has initiated several child survival programs including CB-IMCI, CB-NCP and CB-NIP. Targeted health interventions in most affected population, sustained immunization coverage, incentive to health workers, monitoring and supervision of data reporting will help to improve child health in Nepal.

\section{MDG-5: Improve maternal health}

The maternal mortality has dropped significantly, pointing to a reduction by three- quarters by 2015 .

Target 5 A: Reduce by three-quarters between 1990 and 2015 the maternal mortality rate

Maternal Mortality has come down to 229 in 2010 from 850 in 1990 which suggests that MDG target of 213 is likely to be achieved. Nepal has made good progress in improving the availability of SBA for assisting at delivery which has been attributed as one of the main interventions responsible for reducing maternal mortality. After the introduction of Safe delivery Incentive Program in 2005, institutional delivery has increased. However, MDG target of achieving $60 \%$ of births attended by SBA needs concerted efforts as NDHS 2011 Preliminary findings show that the figures have come to $36 \%$. The 3 delays in seeking, reaching and receiving care needs to be addressed through strong referral networks, strengthening of community based health facilities, expansion of BEOC/CEOC sites, availability of health workers, targeted interventions in poor and marginalized communities.

Target 5 B: Achieve by 2015, universal access to Reproductive health

Contraceptive Prevalence Rate (CPR) has not shown expected improvement over the recent years which have fallen by 1 percentage point from 2006 to $44.2 \%$ in 2011 . This may be due to migration which separates couples. Adolescent pregnancy and motherhood is a major social and health issue as one-fifth of women aged 15-19 years have already given birth or were pregnant with their first child. Adolescent health is not treated as a priority in Nepal. Lack of standards or guidelines on adolescent and youth friendly services substantiate this fact. Unmet need for family planning which is estimated to be about $25 \%$ needs to be addressed and couples should be motivated for utilizing reproductive health services.

\section{MDG-6: Combat HIV, malaria and other diseases}

The target for reversal of HIV/AIDS, malaria and other diseases is likely to be met but will require significantly higher commitments and efforts than are currently being made.

Target 6 A: Have halted by 2015 and begun to reverse the 
spread of HIV/AIDS

The national estimation of HIV infection made in 2007 shows that the HIV epidemic in Nepal appears to be stabilized with HIV prevalence rate of 0.49 in 2007. As of 2009, national estimates indicate that approximately 63,528 adults and children are infected with HIV virus in Nepal with prevalence of about 0.39 in the adult population.

Target 6 B: Achieve by 2015, universal access to treatment for HIV/AIDS for all who need it

Provision of ART is an essential requirement for controlling the epidemic as well as for addressing the human right based approach to caring and support HIV infected individuals. A total of 3,423 individuals or $22.71 \%$ of cases were receiving ART in November, 2009 (NCASC 2009). CB-PMTCT service has also been introduced in the country.

Target 6 C: Have halted by 2015 and begun to reverse the incidence of Malaria, Tuberculosis and other major diseases

Prevalence rate and death rates associated with malaria are decreasing in Nepal. Annual parasite incidence (API) has gone down from 0.56 cases per 1000 of the population in 1999 to 0.14 in 2010. Between 1999 and 2008, number of reported and confirmed malaria cases in Nepal has halved. The trend in anti-malarial treatment has also improved. The issues of migration and drug resistance need to be addressed through vigilant monitoring and evaluation. Distribution of LLIN needs to be further enhanced and provisions of well equipped laboratories are required.

The WHO defined target of a $70 \%$ case detection rate and $85 \%$ treatment success rate for tuberculosis have been achieved through the establishment of strong partnerships with the private sector and community. In 2010, the Case detection rate and treatment success rate were 76 and $90 \%$ respectively. Provided that achievements are consolidated and challenges are addressed, Nepal is likely to meet the targets for Malaria and TB control.

\section{MDG-7: Ensure environmental stability and sustainability}

Environmental sustainability is not being addressed adequately and will require much more effort and resources to achieve the target. Nepal is highly vulnerable to the risks of climate change, although its green house gas emissions is very low. Community based initiatives are essential for effective conservation and sustainable use of biodiversity. Similarly, achievement of the targets for improved drinking water and sanitation requires greater commitment. In Nepal, the level of basic sanitation is unsatisfactory. Energy production and use remain a major challenge for Nepal. Fuel wood is still the main source of energy for cooking purposes.

Target 7 A: Integrate the principles of sustainable development into country policies and reverse the loss of environmental resources
Nepal's contribution to global green house gases is very low (1977.1 Kg per capital) compared to the global average of 3.9 tones. Nepal's consumption of Ozone depleting Substances has also lowered considerably. Nepal's energy use is dominated by traditional source $(84 \%)$. Poor particularly in rural areas have limited access to renewable energy services.

\section{Target 7 B: Reduce biodiversity loss}

Community based conservation has been a boon to reduce biodiversity loss in Nepal which still needs to be strengthened and expanded. Protection of Ecosystems under threat needs greater efforts. Biodiversity documentation has yet to be internalized as a regular government program. Nepal should make efforts to maintain at least $40 \%$ of the natural forest area.

Target 7 C: Halve by 2015, the proportion of people without sustainable access to safe drinking water and basic sanitation

Proportion of population using an improved drinking water source has increased from 46 in 1990 to 80 in 2010 against the MDG target of 73 which has already been achieved. However, efforts are required to increase basic sanitation coverage. Currently, $43 \%$ of the population ( $78 \%$ urban and $35 \%$ rural) has access to improved sanitation facilities against the MDG target of 53 by 2015 which was only $6 \%$ in 1990. Annually 13,000 children die of diarrheal diseases in Nepal which is associated with poor hygiene.

Target 7 D: By 2020, to achieve a significant improvement in lives of slum dwellers.

Rural- urban migration and landless have increased slums in urban areas of Nepal. Problems faced by the slum dwellers are limited supply of clean drinking water, poor sanitation and hygiene. They are vulnerable to preventative communicable diseases.

\section{Goal- 8 : Develop a global partnership for development}

Nepal has been liberal in its approach to partnering with the international community to achieve its development goals. It depends heavily on international support to meet its development budget gap. The trend in terms of absolute volume of foreign aid to Nepal is increasing however, there is a need for making it more effective and mainstreaming it into the national budget.). The MDG need assessment conducted jointly by National Planning Commission and UNDP recently suggested that it will need about 1.395 trillion from 2011 to 2015 among which 451 billion is in deficit. MDG 8 includes following targets.

Target 8A: Developed countries should support developing countries by further developing an open trading and financial system 
Target 8 B: Address the special needs of Least Developed Countries (includes tariff and quota free access for exports, enhanced debt relief and more generous official development assistance for countries committed to reducing poverty.)

Target 8 C: Address the needs of landlocked countries and small island developing countries

Target 8 D: Deal comprehensively with the debt problems of developing countries through national and international measures to make debt sustainable in the long term

Target 8 E: Developing job strategies for youth

Target $8 \mathrm{~F}$ : Providing access to essential drugs in cooperation with pharmaceutical companies.

Target 8 G: Making available the benefits of new technologies especially information and communication in cooperation with the private sector.

\section{Conclusion:}

The MDGs are both national and international commitments. They emphasize commitment of national leaders to a collective responsibility to uphold the principles of human dignity, equality and equity at the global level. There is a moral obligation for the more able to support the weaker so that they can all reach a level where they can compete equally with one another A stronger MDG-aligned, disaggregated data mechanism must also be put in place for better monitoring of MDG progress. Despite contextual difficulties and constraints, Nepal is on track to achieve most of its MDG targets, with a few exceptions, if prevailing trends persist and efforts are continued or improved. However, this aggregate finding should be viewed with caution. Studies should be conducted to dig deeper into the structural disparities across ethnicities, social and economic backgrounds, geography and gender to address the hidden social issues. It is important not only to examine the status of the MDGs and the likelihood of achieving them by 2015 , but also to ask whether the achievements made so far will be sustained in the long term. With the county's transitional political situation as well as a remittance dependent economy, it is essential to ask what the impact of these might be on achievement of the MDGs in 2015 and beyond.

\section{References}

1. DOHS, Annual Report. Department of Health Services, Ministry of Health and Population, 2009/10(2066/67 BS)

2. MOHP, GON, Nepal Demographic and Health Survey 2006, Population Division, Kathmandu Nepal, May 2007

3. MOHP, GON, Nepal Demographic and Health Survey 2011. Summary of Preliminary Findings. Kathmandu: Population Division

4. NCASC/MOH, Cumulative HIV/AIDS Situation of Nepal, NCASC, Ministry of Health and Population, 2010

5. NPC/UNCT (2010), Nepal MDG Progress Report 2010. Kathmandu: National Planning Commission and United Nation Country Team, Nepal,2010 